ORIGINAL ARTICLE

\title{
Urban-rural variation in mortality and hospital admission rates for unintentional injury in Ireland
}

\author{
M Boland, A Staines, P Fitzpatrick, E Scallan
}

Injury Prevention 2005;11:38-42. doi: 10.1136/ip.2004.005371

See end of article for authors' affiliations .....................

Correspondence to: Dr Máirin Boland Department of Public Health Medicine and Epidemiology, University College Dublin, Earlsfort Terrace, Dublin 2, Republic of Ireland; mairin.c. boland@ucd.ie

\begin{abstract}
Objective: To explore urban-rural differences in the mortality and hospital admission rates for unintentional injuries in the Republic of Ireland.

Design: Standardised mortality ratios (SMRs) in residents of urban and non-city areas (called rural areas) from all causes of unintentional injury were calculated using Central Statistics Office mortality data from 1980-2000. Hospital admission data (Hospital In-Patient Enquiry) from 1993-2000 were used to calculate standardised hospital admission ratios (SARs) in urban and rural residents. Population data were obtained from the 1981, 1986, 1991, and 1996 censuses.

Results: The rate of unintentional injury mortality was significantly higher in rural residents for all-cause unintentional injury mortality (SMR 103.0, 95\% confidence interval 101 to 105), and specifically for deaths related to motor vehicle trauma (MVT), drowning, machinery, and firearms. There were significantly higher SMRs in urban residents for falls and poisoning. The rate of unintentional injury hospital admission was significantly higher in rural residents for all-cause unintentional injury (SAR 104.6, $95 \%$ confidence interval 104 to 105) and specifically for injuries from falls, MVT, being struck by or against an object, injuries in pedal cyclists, fire/burn injuries, and machinery injuries. SARs were significantly higher in residents of urban areas for poisoning and injuries in pedestrians.

Conclusions: There are urban-rural differences in mortality and admissions for injuries in Ireland. Possible reasons for the higher rural mortality rates are higher case fatality in MVT and rural exposure to hazardous farm machinery, firearms, and open areas of water. This information could assist in targeting prevention programmes under the proposed National Injury Prevention Strategy.
\end{abstract}

njuries are a major cause of death, hospital admissions, health service expenditure, and long term disability in the Republic of Ireland. Unintentional injuries (including poisoning) are the leading cause of death among young people in Ireland, causing $44.3 \%$ of deaths in the 5-14 year age group and $70 \%$ of deaths in $15-24$ year olds. ${ }^{2}$ Unintentional injury is responsible for approximately 45000 hospital admissions per year in Ireland, representing $8.5 \%$ of all admissions. ${ }^{3}$

All-cause unintentional and intentional injury in Ireland varies substantially at the county level. Lowest standardised mortality rates occur in the east of the country, predominantly an urban environment, including Dublin, the capital city. ${ }^{24}$

Cause specific urban-rural analysis of unintentional injury has not been undertaken before in Ireland and will inform the proposed National Injury Prevention Strategy for Ireland, facilitating targeted injury prevention activity.

This study aimed to identify differences in mortality and hospital admission rates from unintentional injury between urban and rural populations, in order to identify those at higher or lower risk of specific injuries and to make recommendations for prevention.

\section{METHODS}

Two data sets were used in our analyses: Central Statistics Office mortality data, and Hospital In-Patient Enquiry (HIPE) hospital admissions data. Central Statistics Office and HIPE records were included if any International Classification of Diseases, 9th revision, clinical modification (ICD-9-CM) code (primary or other) indicated injury, or if any diagnosis was classified according to the external cause (E codes). ${ }^{6}$ E codes, which range from E800-E999 provide an essential supplementary classification of the cause or mechanism of the injury (for example, fall) and the intent or manner of injury (for example, unintentional).

Deaths and admissions are classified as a motor vehicle trauma (MVT) injury if the person injured received an MVT injury as driver, occupant, or unspecified. ${ }^{7}$ Events are classified as occurring in pedal cyclists and pedestrians because of the category of the person injured, and may also be from involvement in MVT.

\section{Mortality data}

Central Statistics Office mortality data from 1980-2000 were used, coded by cause of death and place of residence. Deaths from adverse events of medical or surgical treatment were included as unintentional injury deaths. There were no missing data, with all area codes being recorded.

\section{Hospital admissions data}

HIPE data from 1993-2000 were used, coded for source or cause of unintentional injury and for place of residence. ${ }^{8}$ The HIPE system is the principal source of national data on discharges from acute public hospitals in Ireland. Hospital chart information is entered by trained HIPE coders into a computer. Each HIPE record represents one episode of care. Although HIPE data are not gathered from private hospitals, almost all acute injury admissions in this country occur via the accident and emergency departments of public hospitals. HIPE data are unlinked, but transfers between hospitals are recorded and were excluded from analysis. ${ }^{9}$

The primary (first recorded) E code was used. If the E code was missing, which occurred in $11.3 \%$ of admissions (59 181

Abbreviations: $\mathrm{Cl}$, confidence interval; HIPE, Hospital In-Patient Enquiry; MVT, motor vehicle trauma; SAR, standardised admission ratio; SMR, standardised mortality ratio 
Table 1 A comparison of urban and rural standardised mortality ratios for the leading causes of unintentional injury for all age groups (1980-2000)

\begin{tabular}{llllll}
\hline & \multicolumn{2}{c}{ No of observed cases } & & & \\
\cline { 2 - 3 } Cause & Urban & Rural & SMR-rural & $95 \% \mathbf{C l}$ & p Value \\
\hline All-cause & 6039 & 12146 & 103.0 & 101 to 105 & $<0.001$ \\
MVT injury & 2453 & 5174 & 107.4 & 105 to 110 & $<0.001$ \\
Fall & 1206 & 2094 & 94.5 & 91 to 99 & $<0.05$ \\
Poisoning & 437 & 348 & 70.2 & 63 to 78 & $<0.001$ \\
Drowning & 350 & 1032 & 117.4 & 110 to 125 & $<0.001$ \\
Fire/burn & 403 & 860 & 101.7 & 95 to 109 & NS \\
Machinery & 38 & 279 & 137.3 & 122 to 154 & $<0.001$ \\
Struck by & 72 & 151 & 105.4 & 89 to 124 & NS \\
Firearm & 10 & 86 & 142.4 & 114 to 176 & $<0.05$ \\
Pedal cyclist & 27 & 65 & 108.2 & 84 to 138 & NS \\
Pedestrian & 28 & 41 & 91.2 & 65 to 124 & NS \\
\hline \multicolumn{7}{l}{ NS, not significant. } & & & &
\end{tabular}

of 520 972), the record was excluded as it could not be classified by cause or intent. There was a similar proportion of missing E codes in rural (10.1\%) and urban (12.7\%) records. Those normally resident outside Ireland (9352 records, 1.8\%) and those with missing area code or no fixed abode (537 records, $0.1 \%$ ) were excluded.

\section{Urban-rural definitions}

A record was defined as urban if place of residence was one of the five defined cities in the Republic of Ireland (Dublin, Cork, Limerick, Galway, and Waterford $)^{10}$ or the surrounding administrative counties of the capital city, Dublin (Dun Laoghaire-Rathdown, Fingal, and South Dublin). All other records were defined as rural.

The urban-rural boundary definitions have been relatively stable over the past two decades, but there has been a population shift towards urban areas, and in 1996, 37\% (1 337271 ) of the population lived in urban areas and 63\% (2 288 816) in rural areas.

\section{Data analysis}

Standardised mortality ratios (SMR) and standardised admission ratios (SAR) were calculated for specific causes of unintentional injury using standard methods, with the appropriate set of age, sex, or year specific rates for the entire country as the standard. Census data from 1981, 1986, 1991, and 1996 were used for standardisation.

The statistical packages SAS $^{11}$ and Stata $^{12}$ were used to analyse data. Data are presented as standardised rates followed by $95 \%$ confidence intervals for the estimated rate.

\section{RESULTS}

\section{Mortality}

The total number of deaths from all-cause unintentional injury from 1980-2000 was 18 185, comprising $73.0 \%$ of all (unintentional and intentional) injury deaths. Of these unintentional injury deaths 6039 (33.2\%) occurred in urban residents and $12146(66.8 \%)$ in rural residents. There were $12026(66.1 \%)$ male and $6159(33.9 \%)$ female deaths, with a per annum mortality rate of 40 per 100000 in males and 20 per 100000 in females. The leading causes of deaths were MVT injuries, falls, drowning, poisoning, and fire/burn injuries.

The rate of all-cause unintentional injury mortality was significantly higher in rural residents, with a SMR of 104.6 (95\% confidence interval (CI) 104 to 105). The number of observed cases and the SMRs for rural populations are shown in table 1 for the 10 leading causes of unintentional injury mortality. Cause specific SMRs were significantly higher in rural residents for MVT injury, drowning, machinery and firearms, and SMRs from falls and poisoning were higher in urban residents. No urban-rural differences were found for deaths from fire/burns, or deaths in pedal cyclists or pedestrians.

Deaths in the under 25 year age group accounted for $29 \%$ of records (5272 of 18185 ) and the urban-rural comparison is shown in table 2 . The relative contribution of drowning to unintentional injury deaths is higher in under 25 year olds compared with the population overall (10.6\% $v 7.5 \%)$. The relative contribution of falls to unintentional injury deaths is much less in this age group $(3.7 \% v 18.1 \%)$, with no urbanrural difference in SMR.

Table 2 A comparison of urban and rural standardised mortality ratios for the leading causes of unintentional injury in under 25 year olds (1980-2000)

\begin{tabular}{|c|c|c|c|c|c|}
\hline \multirow[b]{2}{*}{ Cause } & \multicolumn{2}{|c|}{ No of observed cases } & \multirow[b]{2}{*}{ SMR-rural } & \multirow[b]{2}{*}{$95 \% \mathrm{Cl}$} & \multirow[b]{2}{*}{ p Value } \\
\hline & Urban & Rural & & & \\
\hline All-cause & 1573 & 3699 & 115.6 & 112 to 119 & $<0.001$ \\
\hline$M V T$ injury & 985 & 2353 & 117.4 & 113 to 122 & $<0.001$ \\
\hline Fall & 97 & 99 & 83.2 & 68 to 101 & NS \\
\hline Poisoning & 99 & 81 & 74.4 & 59 to 92 & $<0.001$ \\
\hline Drowning & 121 & 437 & 127.9 & 116 to 140 & $<0.001$ \\
\hline Fire/burn & 102 & 186 & 101.3 & 87 to 117 & NS \\
\hline Machinery & 7 & 93 & 150.1 & 121 to 184 & $<0.001$ \\
\hline Struck by & 22 & 71 & 120.7 & 94 to 152 & NS \\
\hline Firearm & 3 & 40 & 155.1 & 111 to 211 & $<0.05$ \\
\hline Pedal cyclist & 12 & 25 & 109.9 & 71 to 162 & NS \\
\hline Pedestrian & 11 & 13 & 87.0 & 46 to 149 & NS \\
\hline
\end{tabular}




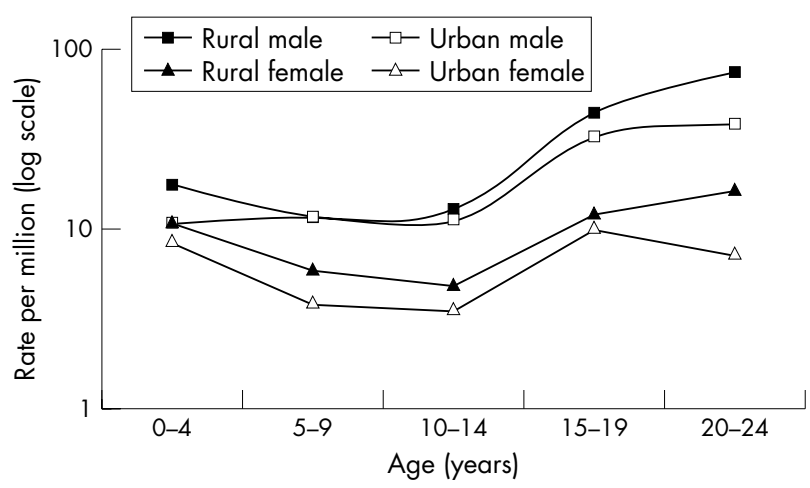

Figure 1 Comparison of SMRs for unintentional injury in males and females by urban and rural area 1980-2000: 0-24 year age group.

Figure 1 shows age specific unintentional injury rates in males and females in the under 25 year age groups. Mortality is consistently higher in males. Mortality is higher in rural males and females compared to their urban counterparts.

\section{Hospital admissions}

The total number of admissions for unintentional injury recorded from 1993-2000 was 348 800, comprising $64.0 \%$ of all (unintentional and intentional) injury admissions. Sixty percent of admissions were male; 68\% (235 809) were rural residents and 32\% (112 991) were urban residents. The admission rate for unintentional injuries was 1670 per 100000 for males and 1050 per 100000 for females. The all-cause unintentional injury SAR was higher in rural residents (SAR 104.6, 95\% C.I 104 to 105). Table 3 shows urban and rural standardised hospital admission ratios for the 10 leading causes of unintentional injury.

For the three main causes of unintentional injury admissions, namely falls, MVT, and being struck by or against an object, there was a higher SAR in those from rural areas. Rural residents had a higher SAR for injuries to pedal cyclists, fire or burn injuries, and machinery injuries. SARs for poisoning and pedestrian injury were significantly higher in urban residents. The SAR for drowning and firearm injury did not differ by population.

In the under 25 year age group (table 4 ) falls comprise the same proportion of admissions as in the population overall $(33.8 \% \vee 33.8 \%)$ but the urban SAR for falls is higher, whereas the rural SAR for falls in the entire population is higher. For poisoning, the SAR in under 25 year olds shows no urban-rural difference, whereas the rural SAR is lower for the entire population.
Figure 2 shows admission rates in the under 25 year age group. Admission rates are consistently higher in males. For both males and females higher admission rates occur in children from urban areas and adolescents from rural areas.

\section{DISCUSSION}

The Republic of Ireland is a small country, with an area of $70282 \mathrm{~km}^{2}$ and is predominantly rural, with few major cities. Compared with other European countries, Ireland is sparsely populated, with an average of 52 inhabitants per $\mathrm{km}^{2}$. While the urban-rural boundaries have remained stable over 20 years, there has been a gradual shift in the population to urban areas, particularly over the past decade. We found that the death rate and the hospital admission rate for all-cause unintentional injury was higher in the rural population in Ireland, similar to the United States. ${ }^{13}$ The cause specific analysis showed further urban-rural variation.

\section{Urban-rural cause specific injury differences}

MVT is the leading cause of death from unintentional injury in Ireland, with a death rate of 10.1 per 100000 in 2002. ${ }^{14}$ Most MVT injuries occur close to place of residence, but it is acknowledged that major injuries could occur elsewhere. We found the admission rate for MVT and the mortality rate are higher in rural residents. In the Republic of Ireland only $2 \%$ of traffic is on motorways ${ }^{15}$ and a combination of speed, drink-driving, poor lighting, low seat belt use, narrow country roads, and use of farm vehicles may explain some of the rural excess. ${ }^{14} 16$ Differences in case fatality rates may also be a factor, as may be the reduced access for the rural population to emergency care and to public transport.

For falls, the admission rate is higher in rural residents, but the death rate is higher in city residents. While these findings hold for the total population, no such differences were found in those under 25 years; the small number of falls in the younger age group may account for this. The use of accident and emergency observation wards in large city hospitals may reduce admissions for falls for urban residents.

Poisoning admission rates and mortality rates are higher in urban residents, concurring with figures from the United States. ${ }^{17}$ Possibly, parasuicide attempts may be miscoded as unintentional poisoning in urban residents.

Drowning deaths were significantly higher in rural residents. Private pools are uncommon in Ireland. Recreational habits, the presence of unfenced bodies of water, and inability to swim are the likely contributory factors. This rural association has been previously described in Canada and Scotland..$^{18} 19$

We found unintentional fire/burns injury admissions to be higher in rural populations. There were greater numbers of

\begin{tabular}{|c|c|c|c|c|c|}
\hline \multirow[b]{2}{*}{ Cause } & \multicolumn{2}{|c|}{ No of observed cases } & \multirow[b]{2}{*}{ SAR-rural } & \multirow[b]{2}{*}{$95 \% \mathrm{Cl}$} & \multirow[b]{2}{*}{$\mathrm{p}$ Value } \\
\hline & Urban & Rural & & & \\
\hline All-cause & 112991 & 348800 & 104.6 & 104 to 105 & $<0.001$ \\
\hline Fall & 53987 & 102464 & 101.3 & 101 to 102 & $<0.001$ \\
\hline MVT & 12983 & 36965 & 119.8 & 119 to 121 & $<0.001$ \\
\hline Struck by & 10451 & 24347 & 111.3 & 110 to 113 & $<0.001$ \\
\hline Poisoning & 8419 & 12326 & 95.1 & 93 to 97 & $<0.001$ \\
\hline Pedal cyclist & 2936 & 6243 & 104.5 & 102 to 107 & $<0.001$ \\
\hline Fire/burn & 2265 & 4959 & 107.6 & 105 to 111 & $<0.001$ \\
\hline Machinery & 1079 & 4911 & 130.5 & 127 to 134 & $<0.001$ \\
\hline Pedestrian & 670 & 1026 & 93.3 & 88 to 99 & $<0.05$ \\
\hline Drowning & 130 & 215 & 99.4 & 87 to 114 & NS \\
\hline Firearm & 135 & 199 & 95.6 & 83 to 110 & NS \\
\hline
\end{tabular}


Table 4 A comparison of urban and rural standardised hospital admission ratios for the leading causes of unintentional injury in under 25 year olds (1993-2000)

\begin{tabular}{llllll}
\hline & \multicolumn{3}{l}{ No of observed cases } & & \\
\cline { 2 - 3 } Cause & Urban & Rural & SAR-rural & $95 \% \mathrm{Cl}$ & p Value \\
\hline All-cause & 29599 & 56874 & 103.8 & 103 to 105 & $<0.001$ \\
Fall & 10965 & 18324 & 97.3 & 96 to 99 & $<0.001$ \\
MVT injury & 3293 & 9024 & 119.9 & 117 to 122 & $<0.001$ \\
Struck by & 4007 & 8616 & 107.6 & 105 to 110 & $<0.001$ \\
Poisoning & 3197 & 5075 & 97.9 & 85 to 101 & NS \\
Pedal cyclist & 1470 & 3066 & 103.3 & 100 to 107 & NS \\
Fire/burn & 226 & 371 & 97.6 & 88 to 108 & NS \\
Machinery & 180 & 854 & 133.8 & 125 to 143 & $<0.001$ \\
Pedestrian & 260 & 395 & 92.5 & 84 to 102 & NS \\
Drowning & 33 & 67 & 108.0 & 84 to 137 & NS \\
Firearm & 26 & 44 & 101.8 & 74 to 137 & NS \\
\hline NS, not significant. & & & &
\end{tabular}

deaths from burns in rural residents, but this difference did not reach statistical significance. Other research found that burns occur more often in rural areas, and that burns experienced in rural areas may be more severe and cause more deaths. ${ }^{20}$ Poorer access to emergency services may be implicated here.

Both hospital admissions and deaths were higher in rural residents for machinery injuries. Most farm accidents are machinery related ${ }^{21}$ and exposure to hazardous agricultural machinery is a likely contributor to the higher rural rates found. The Republic of Ireland is predominantly rural, with a high proportion of the labour force engaged in work related to agriculture. In addition adolescent or young adult family members often work on farms, especially at times of peak activity in the farming year.

Ireland has very restrictive gun laws, and numbers of deaths are relatively low. There was a significant excess of firearm deaths in rural residents, which has been found previously. ${ }^{22}$ Our finding may reflect the greater number of firearms held on farms and in the countryside for recreational purposes. Many of the serious firearm injuries will result in death before hospital admission.

Other research has found higher mortality in pedestrians in the rural setting, ${ }^{23}$ with poorly lit roads and less favourable health care emerging as significant variables. We found no urban-rural difference in the mortality rate for pedestrian or pedal cyclist injury. Rates of walking are higher in urban areas, as absence of footpaths and poor lighting in some rural areas is unsupportive of pedestrians. This may explain the higher admission rate for pedestrian injury in city residents. Cycling rates are higher in urban areas, and we found admission rates to be significantly lower for pedal cyclist injuries in urban residents. This concurs with the finding by Jacobsen that the likelihood that a given person walking or

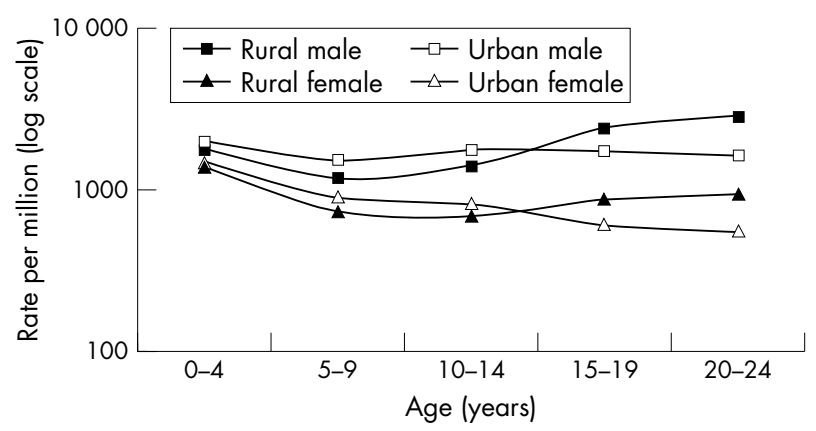

Figure 2 Comparison of SARs from unintentional injury in males and females by urban and rural area 1993-2000: 0-24 year age group.

\section{Key points}

- Unintentional injury standardised mortality and hospital admission ratios are higher in rural residents in Ireland for all-cause unintentional injury.

- Higher SMRs occur in rural populations for deaths related to motor vehicle trauma, drowning, machinery and firearms.

- Higher SMRs occur in urban populations for falls and poisoning.

- A policy of targeted injury prevention activity needs to be implemented.

bicycling will be struck by a motorist varies inversely with the amount of walking or bicycling. ${ }^{24}$

\section{Data limitations}

This study used the most complete datasets available in Ireland for unintentional injury prevention research. ${ }^{25}$ Data on social class and poverty, an important injury risk factor, were not available from routine data sources. Emergency department records and general practitioner data are not routinely collated in Ireland; these are a rich but little used source of morbidity information to complement mortality data. Other routine data sources such as the police force (An Garda Siochána) and the National Roads Authority exist but are not mutually compatible and are inadequate in their current format for epidemiological purposes. ${ }^{26}$

We sought to maximise ascertainment of admission data by including records with an E code recorded for any of the six possible diagnoses and including repeat admissions to avoid underestimation of injuries that may recur, such as burns or falls. ${ }^{9}$ It is possible, however, that repeat admissions for treatment of the same injury led to overestimation.

\section{CONCLUSIONS}

The public health approach to injury control must continue to focus on developing combinations of educational strategies, environmental modifications, legislation, and engineering techniques $^{27}$ together with improvement of existing data sources. Narrowly targeted injury prevention programmes focused on a particular group and a particular injury have been found to be more successful than broad diffuse programmes. ${ }^{16}$ The benefit of identification of populations with higher rates of cause specific unintentional injury deaths or hospital admissions is that likely causal factors and pathways for prevention may be highlighted, facilitating 
targeted health promotion activity. ${ }^{13}$ One existing programme in this country is the accident prevention education programme aimed specifically at the farming community. Further targeting should occur with, for example, a water safety programme in relation to unsupervised rural settings and boating. Accident prevention programmes could be prioritised with reference to the specific risk highest in urban and rural populations. Our findings have implications for health care policy makers responsible for planning injury control strategies and will, it is hoped, influence the proposed National Injury Prevention Strategy for Ireland.

\section{ACKNOWLEDGEMENTS}

This research was funded by the Health Research Board. We would like to thank the Economic and Social Research Institute for the provision of Hospital In-Patient Enquiry data and the Central Statistics Office for providing mortality data. We are grateful to members of the Injury in Ireland group, specifically Dominique Crowley, Lourda Geoghegan, and Majda al-Fallah who helped to clarify the presentation.

\section{Authors' affiliations}

M Boland, A Staines, P Fitzpatrick, E Scallan, Department of Public Health Medicine and Epidemiology, University College Dublin, Dublin, Republic of Ireland

\section{REFERENCES}

1 Laffoy M, Igoe D, O'Herlihy B. Accidental injury in Ireland-priorities for prevention. Dublin: Office for Health Gain, 1995.

2 Scallan E, Staines A, Fitzpatrick P, et al. Injury in Ireland. Dublin: Department of Public Health Medicine and Epidemiology, University College, Dublin, 2001.

3 Scallan E, Staines A, Fitzpatrick $P$, et al. Unintentional injury in Ireland: a comparison of mortality and morbidity data. J Public Health 2004;26:6-7.

4 Barry J, Sinclair H, Kelly A, et al. Inequalities in Ireland-hard facts. Dublin: Department of Community Health and General Practice, Trinity College, Dublin, 2001

5 Department of Health and Children. Quality and fairness - a health strategy for you. Dublin: Government Publications, 2003.
6 Centers for Disease Control and Prevention. International classification of diseases, 9th revision, clinical modifications. Hyattsville, MD: CDC, 1994. 7 Recommended framework for presenting injury mortality data. MMWR Recomm Rep 1997;46(RR-14): 1-30.

8 Economic and Social Research Institute. Activity in acute public hospitals in Ireland 1990-1999. Dublin: HIPE and NPRS Unit, Department of Health and Children, 2002

9 Boufous G, Williamson A. Reporting of the incidence of hospitalised injuries: numerator issues. Inj Prev 2003;9:370-5.

10 Planning and Development Act. Statutory Instrument No 30: Irish Statute Book Database, 2000.

11 SAS Institute. SAS user's guide (program). 5 Version. Cary, NC: SAS Institute Inc, 1985.

12 Stata Corporation. Stata statistical software (program). 7.0 Version. College Station, TX: Stata Corporation, 2001

13 Waller AE, Baker SP, Szocka A. Childhood injury deaths: national analysis and geographic variations. Am J Public Health 1989;79:310-5.

14 Organisation for Economic Co-operation and Development, BASt. International road traffic and accident database. Paris: OECD, 2002.

15 Page Y. A statistical model to compare road mortality in OECD countries. Accid Anal Prev 2001;33:371-85.

16 Rivara FP, Aitken M. Prevention of injuries to children and adolescents. Adv Pediatr 1998;45:37-72.

17 National Center for Health Statistics. Health, United States, 1996-1997 and injury chartbook. Rockville, MD: NCHS, 1997.

18 MacWilliam L, Mao Y, Nicholls E, et al. Fatal accidental childhood injuries in Canada. Can J Public Health 1987;78:129-35.

19 Campbell H, O'Driscoll S. Health promotion review: accident prevention. Leisure and water accidents in Scotland. Glasgow: Scottish Needs Assessment Programme, Scottish Forum for Public Health Medicine, 1995.

20 Rogers FB, Shackford SR, Hoyt DB, et al. Trauma deaths in a mature urban vs rural trauma system. A comparison. Arch Surg 1997;132:376-81, discussion $381-2$.

21 Cameron D, Bishop C. Farm accidents in adults. BMJ 1992;305:25-6.

22 Dresang LT. Gun deaths in rural and urban settings: recommendations for prevention. J Am Board Fam Pract 2001;14:2:107-15.

23 Miles-Doan R, Kelly S. Inequities in health care and survival after injury among pedestrians: explaining the urban/rural differential. J Rural Health 1995; 11:177-84.

24 Jacobsen PL. Safety in numbers: more walkers and bicyclists, safer walking and bicycling. Inj Prev 2003;9:205-9.

25 Cummins P, Koepsell T, Mueller B. Methodological challenges in injury epidemiology and prevention reseacrh. Ann Rev Public Health 1995; 16:381-400.

26 Street JT, Winter D, Buckley S, et al. Trauma on rural roads: the role of a peripheral hospital. Injury 1999;30:337-40.

27 National Committee for Injury Prevention and Control. Injury prevention meeting the challenge. Am J Prev Med 1989;5(3 suppl): 1-303.

LACUNAE

Revocation of US safety rules on rat poison formulation

A ctivist groups have filed suit against the US Environmental Protection Agency (EPA), alleging that the agency's revocation of safety rules on the formulation of rat poison has put children at risk. The plaintiffs are calling for the reinstatement of federal controls that required rat poisons to contain an ingredient that makes the poison taste bitter and a dye to make it obvious when a child has ingested the poison. The controls were abandoned by the EPA in 2001 after consultations with the manufacturers led to a mutual agreement to rescind the requirements. Millions of pounds of rat poisons are applied nationally each year-about 800 pounds of rat poison have been used in one New York City housing project alone this year, and the poisons are also used at schools and parks. More than 50000 children under age 6 were sickened by eating rodent control toxins this year, more than triple the number reported in the first full year after the safety measures were adopted, according to the American Association of Poison Control Centers. EPA officials said they are reviewing the complaint and will respond accordingly. 